\title{
High Resolution MR Angiography of the Posterior Cerebral Circulation: Variants, Incidence and Clinical Impact
}

\author{
Argyro Mazioti, Nikolaos Economopoulos, Olympia Papakonstantinou, Christina Kontopoulou, \\ Dimitrios Filippiadis, Aristodimos Maratsos, Nikolaos Kelekis, Efthymia Alexopoulou \\ 2nd Radiology Department, General University Hospital “Attikon”, Chaidari-Athens, Greece \\ Email: argyromazioti@yahoo.gr
}

Received November 15, 2013; revised December 15, 2013; accepted December 22, 2013

Copyright (C) 2013 Argyro Mazioti et al. This is an open access article distributed under the Creative Commons Attribution License, which permits unrestricted use, distribution, and reproduction in any medium, provided the original work is properly cited. In accordance of the Creative Commons Attribution License all Copyrights (C) 2013 are reserved for SCIRP and the owner of the intellectual property Argyro Mazioti et al. All Copyright (C) 2013 are guarded by law and by SCIRP as a guardian.

\begin{abstract}
Objective: In the embryonic period, several developmental anomalies of the posterior cerebral circulation might occur. Digital subtractive angiography used to be the imaging technique of choice for the illustration of such variations. Nowadays, the development of MR imaging has led to a new entry in the diagnostic archer's quivery, the MR angiography, with which most of these variations may be diagnosed. Purpose of this study is to illustrate these anatomic variants, their incidence and their potential clinical significance. Materials and Methods: We retrospectively reviewed $282 \mathrm{MR}$ angiographies performed in our institution, in order to assess the posterior cerebral circulation. The imaging findings (including both normal development and variations) were depicted. Results: In our study 61/282 (21.63\%) MR angiographies were positive for imaging findings concerning variations of the vertebrobasilar system. These variations included abnormal origin of the vertebral artery $(0.7 \%)$, unilateral aplasia or hypoplasia $(8.86 \%)$, unilateral aplasia or hypoplasia of the distal part of the vertebral artery (3.85\%), and unilateral or bilateral fetal posterior cerebral artery (7.7\%). These results show that anatomic variations of the posterior cerebral circulation are not very uncommon in the population. Conclusion: High resolution Magnetic Resonance Angiography provides excellent interpretation of the vertebral arteries, allowing depiction of all anatomic variations. Knowing these anatomic variations is important, especially for clinicians and patients planning a surgical operation or an interventional radiology technique. Furthermore, it contributes to avoiding potential diagnostic pitfalls or to explaining unusual acute vascular cerebral events.
\end{abstract}

Keywords: MRA; Vertebral Arteries; Variants

\section{Introduction}

During embryonic period, several developmental anomalies of the vertebrobasilar system might occur. Knowing these anatomic variations is important, especially for clinicians and patients planning a surgical operation or an interventional radiology technique. Furthermore, the knowledge of a variation might prevent unnecessary imaging studies or contribute to avoiding diagnostic pitfalls.

Some years ago digital subtractive angiography (DSA) was the imaging technique of choice for the illustration of such variations. The potential complications of this technique along with the effect of ionizing radiation and the development of MR imaging have led to a new entry in the diagnostic archer's quivery, the MR angiography, with which most of these variations may be diagnosed.

Purpose of this study is to review our cases and to report not only anatomic variations but the occurrence and potential clinical significance as well.

\section{Materials and Methods}

During our study we retrospectively reviewed 282 MR Angiographies of the neck arteries and the circle of Willis which were performed between 2003 and 2010 in our institution. The vast majority of the aforementioned patients were submitted to our department for investigation of atherosclerotic carotid disease. All imaging was performed on a 1.5-T MRI Scanner (Philips Medical, Intera). The routine MRI protocol included: a survey in 
sagittal plane, a 3D SPGR sequence without contrast media in coronal plane (mask), a bolus track (intravenous injection of gadolinium with fluoroscopic triggering in coronal plane) and a 3D SPGR after intravenous gadolinium injection in coronal plane (first pass) with parameters TR: $4.5 \mathrm{~ms}$, TE: $1.5 \mathrm{~ms}$, flip angle $30^{\circ}$, Field Of View: $32 \times 32$, slice thickness $1.4 \mathrm{~mm}$, slice spacing 0.7 $\mathrm{mm}$, central k-space filling, acquisition matrix $336 \times 336$ and reconstruction matrix $512 \times 512$. Subtraction images were performed. A dedicated workstation was used for the evaluation of the MR Angiograms employing post processing techniques, such as maximum intensity projection (MIP) and planar reformates (Multiplanar reformat MPR, curve planar reformat $\mathrm{CPR}$ ).

We classified vertebral artery (VA) aplasia when the vessel was not imaged and hypoplasia when its diameter was $<2 \mathrm{~mm}[1]$.

Unilateral distal aplasia or hypoplasia of the VA was recorded when the portion of the VA distal to the origin of the posterior inferior cerebellar artery (PICA) was either not seen or its caliber was smaller or equal to that of the anterior inferior cerebellar artery (AICA) respectively.

As fetal type posterior cerebral arteries (PCA) were classified all the cases where the vessel stems from the internal carotid artery (ICA) had larger diameters than those of the ipsilateral precommunicating segment of the posterior cerebral artery (P1) or continued distally as the posterior cerebral artery. On the other hand, as posterior communicating arteries were classified all the vessel stems arising from the internal carotid artery (ICA) and having diameters equal to or smaller than that of the ipsilateral precommunicating segments of the posterior cerebral arteries.

\section{Results}

In our study $61 / 282(21.63 \%)$ MR angiographies were positive for imaging findings upon variations of the vertebrobasilar system. These variations included abnormal origin of the vertebral artery $(0.7 \%)$, unilateral aplasia or hypoplasia $(8.86 \%)$, unilateral aplasia or hypoplasia of the distal part of the vertebral artery $(3.85 \%)$, and unilateral or bilateral fetal posterior cerebral artery $(7.7 \%)$. Our findings are presented in Table 1.

Abnormal origin of the vertebral artery was found in two patients. In the first, MR Angiography revealed a right VA originating from the innominate artery, as well as fetal right PCA. In the second patient, the left VA originated from the aortic arch between the left common carotid artery and the left subclavian artery (Figure 1). This patient also had a unilateral fetal PCA.

In two patients, the whole vertebral artery was absent. In another two patients only the distal vertebral artery after PICA was absent. One of them had also a high grade stenosis of the contralateral VA (Figure 2). This is why this patient subsequently presented with a right mesencephalic and right thalamic infarct.

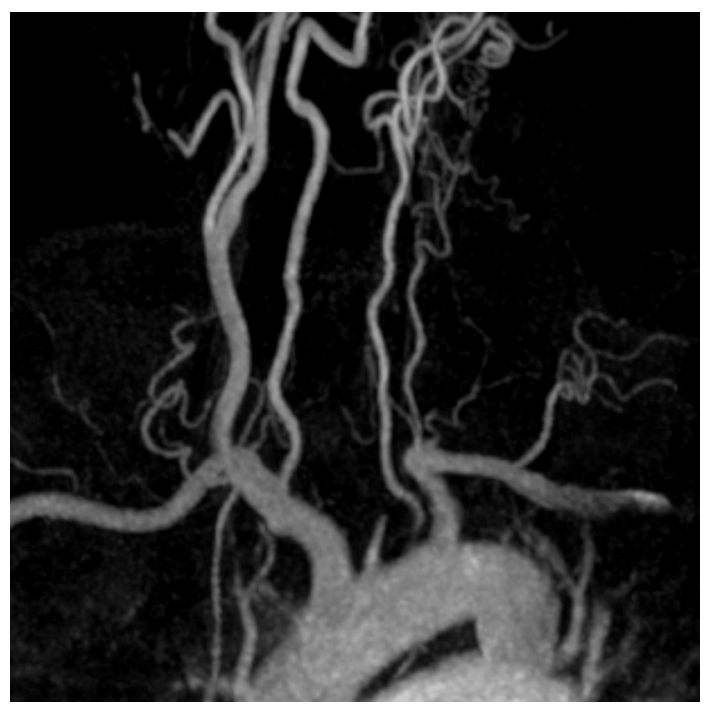

Figure 1. Maximum Intensity Projection (MIP) image in the sagittal plane. There is anomalous origin of the left vertebral artery from the aortic arch between the left common carotid artery and the left subclavian artery.

Table 1. Vertebrobasilar system anatomic variations in $282 \mathrm{MR}$ angiographies.

\begin{tabular}{|c|c|c|c|}
\hline Type of Variation & Number of patients & Concomitant features & Occurrence $(\%)$ \\
\hline \multicolumn{4}{|l|}{ Anomalous origin of VA } \\
\hline -Right VA origin from innominate & 1 & Fetal right $\mathrm{PCA}$ & 0.35 \\
\hline Unilateral VA aplasia & 2 & - & 0.7 \\
\hline Unilateral VA hypoplasia & 23 & bovine arch ( 2 patients) & 8.16 \\
\hline Unilateral distal VA aplasia & 2 & bovine $\operatorname{arch}(1$ patient $)$ & 0.35 \\
\hline Unilateral distal VA hypoplasia & 10 & fetal PCA (2 patients) & 3.5 \\
\hline \multicolumn{4}{|l|}{ Fetal PCA } \\
\hline -Unilateral & 20 & hypoplastic distal VA (1 patient) bovine arch (1 patient) & 7 \\
\hline -Bilateral & 2 & hypoplastic VA (1 patient) & 0.7 \\
\hline
\end{tabular}




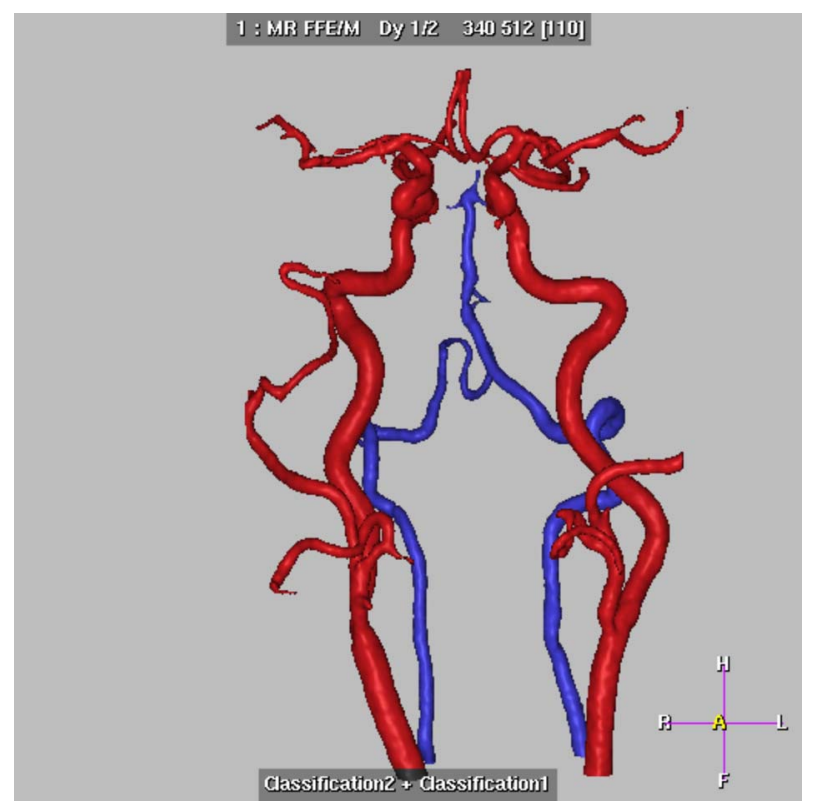

Figure 2. MRA with 3D Reconstruction in the coronal plane. There is absence of the distal part of the right VA beyond PICA origin. There is also a high grade stenosis of the distal part of the left vertebral artery. This patient subsequently presented with a right mesencephalic and right thalamic infarct.

A significant number of patients presented with a hypoplastic vertebral artery, either with whole vessel hypoplasia (23 patients) or with hypoplastic distal VA (10 patients). Unilateral fetal PCA was noted in 20 patients and bilateral fetal PCA in 2 patients. It is worth noting that one patient with a left fetal PCA also had a high grade stenosis in the proximal part of the left ICA. Before intervention, this patient presented with acute neurologic symptoms due to acute infarcts in watershed area and in the posterior circulation. This was explained by embolic material from the left atheromatous ICA, the vessel which also supplied the posterior circulation in this patient (Figures 3(a)-(d)).

\section{Discussion}

High resolution Magnetic Resonance Angiography was initially employed as an alternative non invasive imaging method, comparing with the invasive Digital Subtraction Angiography, for the estimation of carotid artery stenosis. The main purpose of this method was to attain the smallest possible voxel size, for accurate depiction of the degree of stenosis, based on the North American Symptomatic Carotid Endarterectomy Trial (NASCET), European Carotid Surgery Trial (ECST), or Carotid Stenosis Index (CSI) criteria. The collateral benefit in the development of this method was the better interpretation of the vertebral arteries, which are smaller caliber vessels than carotid arteries. So, High Resolution Magnetic Reso-

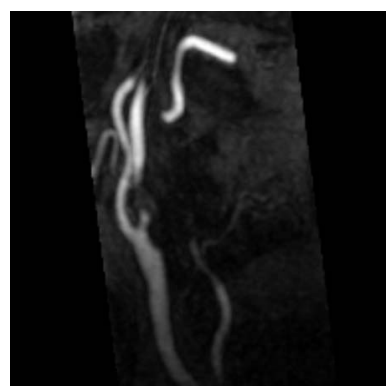

(a)

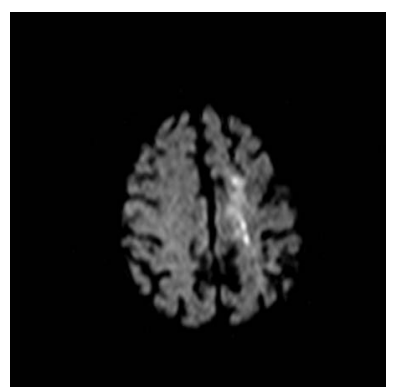

(c)

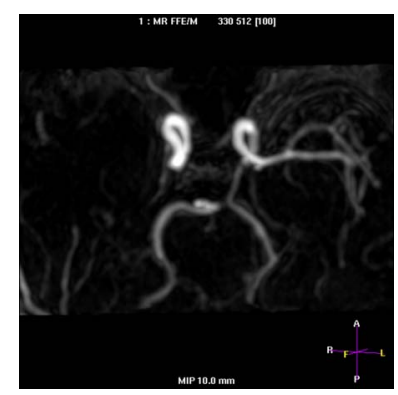

(b)

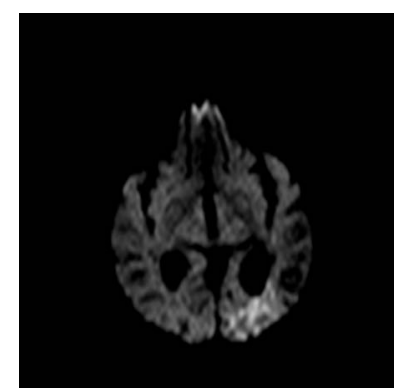

(d)
Figure 3. (a) Maximum Intensity Projection (MIP) image in the sagittal plane illustrating a high grade stenosis in the proximal part of the left internal carotid artery; (b) MIP image in the axial plane (same patient) illustrating the left PCA originating from the ipsilateral ICA; Figure 3(c) and (d): Brain MRI, diffusion image, illustrating acute infarct in watershed area (c) and also in the posterior circulation in this patient (d).

nance Angiography became an extremely helpful tool for non invasive imaging of the vertebrobasilar system.

During the embryonic period, eight pairs of intersegmental cervical arteries form the primitive carotid-vertebral anastomoses with the most caudal intersegmental artery being defined as the primitive proatlantal artery. The vertebral arteries are developed as plexiform longitudinal anastomoses among the six cervical intersegmental arteries (C1 - C6). Apart from the sixth intersegmental artery (which progress to the adult subclavian artery), the rest proximal connections among the intersegmental arteries and the dorsal aorta regress. Basilar artery (BA) is formed in the 5- to 9-mm embryo by the fusion of the longitudinal vertebral arteries across the midline [2].

Several anatomic variations of the vertebral arteries have been reported in the literature. However, most studies refer either to certain variations reported during a study of the circle of Willis (for example fetal PCA variant) or describe isolated case reports. Furthermore, the incidence of these anatomic variants differs in these various studies due to the different methods used (autopsy, angiography and Doppler ultrasound).

The results of autopsy studies concerning the origin of the vertebral arteries, report that the most common variant is a left VA with a direct origin from the aortic arch 
located between the left common carotid artery and left subclavian artery, with an incidence of $1.6 \%$ - 5.8\% [3-7]. The lowest percentage has been reported in an Indian study $(1.6 \%)$ [5]. Incidence of this variant in our study was much lower $(0.35 \%)$ and close to the results of a recent angiographic study in Greece where the reported incidence was $0.79 \%$ [6]. Furthermore, in our study, a right VA arising from the innominate artery was reported at $0.35 \%$ of the cases. Up to date as far as we know, throughout the literature there are only case reports describing this specific variant [8].

Unilateral asymmetry or severe hypoplasia of the VA is governed by a prevalence which is up to date unknown due to differences in the definitions and the examining techniques used. Based on autopsy findings and angiograms, the frequency of vertebral artery hypoplasia has been reported to range from 2 to $6 \%$, except in Asia, where it was higher $(15.7 \%-20.2 \%)$ [9-14]. Furthermore, two previous MRA studies report an incidence of $26.5 \%$ and $10.4 \%$ respectively $[15,16]$. Our results $(8.15 \%)$ are close to those reported in the population of Taiwan by Chuang et al. [16].

Up to our knowledge there is no article in the literature reporting the incidence of complete VA aplasia. However, unilateral distal VA aplasia has been reported with an incidence of $0.2 \%$ in angiographic studies or with $4.6 \%$ in a recent MR study (combining BPAS-MRI and MRA) in asymptomatic patients $[4,17,18]$. The authors of the latter study could not explain this large difference. Our results $(0.35 \%)$ are quite closer to those reported in the angiographic studies. In the same MR study, a 5.06\% incidence of a hypoplastic distal VA was reported [18]. Furthermore, another MR study (also combining BPASMRI and MRA) reported an incidence of unilateral distal hypoplasia or aplasia of the VA of $6.8 \%$ [19].

Finally, the incidence of fetal PCA has been reported to be $10 \%$ on the right, $10 \%$ on the left side and $8 \%$ bilaterally $[20,21]$. The reported incidence in our study is much lower ( $7 \%$ unilateral and $0.7 \%$ bilateral).

In conclusion, our study showed that anatomic variations of the vertebral arteries are not very uncommon in the population, since almost one in five patients presented with a variation. Diagnosis of these variations is very significant. Variations of the VA origin may predispose to intracranial aneurysms formation although they do not result in cerebral hemodynamic perturbation predisposing to cerebrovascular disorders [8]. This is why such patients should undergo a thorough search for coexisting aneurysms [22]. Additionally, VA origin variants are important in order to avoid potential diagnostic pitfalls or in order to properly plan an aortic arch surgery/endovascular intervention.

A lot of controversy is raised concerning the clinical significance of VA hypoplasia (VAH) and whether it should be regarded as a normal variant or a predisposing factor for posterior circulation ischemia [23-27]. Giannopoulos et al considers VAH as a normal variant when solely encountered and as a contributing factor to posterior circulation stroke when it is combined to other risk factors [30]. Furthermore, there is some evidence supporting an association among migraine with aura and VAH $[28,29]$.

In the presence of fetal PCA variant, since carotid artery is the dominant blood supplier, thrombosis or embolism of the ICA may cause ischemia or infarction of the occipital pole [30-33]. Thus, MR angiography is signifycant in patients with occipital lobe ischemia, especially in the cases where carotid endarterectomy is a therapeutic option. In addition, knowledge of this variant is important in planning therapy of a cavernous carotid aneurysm, fistula or carotid sheath tumors (carotid ligation or balloon occlusion).

\section{Conclusion}

Variations of the vertebrobasilar system are quite common imaging finding of MR angiographies if one considers that they constitute approximately one fifth of the angiographies included in our study. These variations include abnormal origin, aplasia or hypoplasia (either total or of the distal part of the vertebral artery), persistent embryonic branches and fetal PCA. Knowledge of these anatomic variations is important not only for the design of a surgical operation or of an interventional radiology technique but also to avoid potential diagnostic pitfalls or to explain unusual acute vascular cerebral events.

\section{REFERENCES}

[1] F. Fazekas, K. Niederkorn, F. Ebner and E. Díez-Tejedor, "Relevance of Neuroimaging in the Evaluation of Cerebral Ischemia," Cerebrovascular Diseases, Vol. 27, Suppl. 1, 2009, pp. 1-8.

http://dx.doi.org/10.1159/000200436

[2] S. R. Satti, C. A. Cerniglia and R. A. Koenigsberg, "Cervical Vertebral Artery Variations: An Anatomic Study," AJNR, Vol. 28, No. 5, 2007, pp. 976-980.

[3] T. H. Newton and R. L. Mani, "The Vertebral Artery," In: T. H. Newton and D. G. Potts, Eds., Radiology of the Skull and Brain, Mosby, St. Louis, 1974, pp. 1659-1672.

[4] K. Yamaki, T. Saga, T. Hirata, M. Sakaino, M. Nohno, S. Kobayashi, et al., "Anatomical Study of the Vertebral Japanese Adults," Anatomical Science International, Vol. 81, No. 2, 2006, pp. 100-106. http://dx.doi.org/10.1111/j.1447-073X.2006.00133.x

[5] S. R. Nayak, M. M. Pai, L. V. Prabhu, S. D'Costa and P. Shetty, "Anatomical Organization of Aortic Arch Variations in the India: Embryological Basis and Review," Jornal Vascular Brasileiro, Vol. 5, No. 2, 2006, pp. 95- 
100.

[6] K. I. Natsis, I. A. Tsitouridis, M. V. Didagelos, A. A. Fillipidis , K. G. Vlasis and P. D. Tsikaras, "Anatomical Variations in the Branches of the Human Aortic Arch in 633 Angiographies: Clinical Significance and Literature Review," Surgical and Radiologic Anatomy, Vol. 31, No. 5, pp. 2009, 319-323.

[7] M. Müller, B. L. Schmitz, S. Pauls, M. Schick, S. Röhrer, T. Kapapa, et al., "Variations of the Aortic Arch-A Study on the Most Common Branching Patterns," Acta Radiologica, Vol. 52, No. 7, 2011, pp. 738-774. http://dx.doi.org/10.1258/ar.2011.110013

[8] A. J. Lemke, G. Benndorf, T. Liebig and R. Felix, "Anomalous Origin of the Right Vertebral Artery: Review of the Literature and Case Report of the Right Vertebral Artery Origin Distal to the Left Subclavian Artery," American Journal of Neuroradiology, Vol. 20, No. 7, 1999, pp. 1318-1321.

[9] E. Seidel, B. M. Eicke, B. Tettenborn and F. Krummenauer, "Reference Values for Vertebral Artery Flow Volume by Duplex Sonography in Young and Elderly Adults," Stroke, Vol. 30, No. 12, 1999, pp. 2692-2696. http://dx.doi.org/10.1161/01.STR.30.12.2692

[10] K. Saito, K. Kimura, K. Nagatsuka, K. Nagano, K. Minematsu, S. Ueno, et al., "Vertebral Artery Occlusion in Duplex Color-Coded Ultrasonography," Stroke, Vol. 35, No. 5, 2004, pp. 1068-1072. http://dx.doi.org/10.1161/01.STR.0000125857.63427.59

[11] B. Oder, W. Oder, W. Lang, E. Marschnigg and L. Deecke, "Hypoplasia, Stenosis and Other Alterations of the Vertebral Artery: DOES Impaired Blood Rheology Manifest a Hidden Disease?" Acta Neurologica Scandinavica, Vol. 97, No. 6, 1998, pp. 398-403. http://dx.doi.org/10.1111/j.1600-0404.1998.tb05973.x

[12] Y. M. Chuang, Y. C. Huang, H. H. Hu and C. Y. Yang, "Toward a Further Elucidation: Role of Vertebral Artery Hypoplasia in Acute Ischemic Stroke," European Neurology, Vol. 55, No. 4, 2006, pp. 193-197. http://dx.doi.org/10.1159/000093868

[13] A. Songur, Y. Gonul, O. A. Ozen, H. Kucuker, I. Uzun, O. Bas, et al., "Variations in the Intracranial Vertebrobasilar System," Surgical and Radiologic Anatomy, Vol. 30, No. 3, 2008, pp. 257-264. http://dx.doi.org/10.1007/s00276-008-0309-6

[14] I. C. Tsai, W. S. Tzeng, T. Lee, S. L. Jan, Y. C. Fu , M. C. Chen, et al., "Vertebral and Carotid Artery Anomalies in Patients with Aberrant Right Subclavian Arteries," Pediatric Radiology, Vol. 37, No. 10, 2007, pp. 1007-1012. http://dx.doi.org/10.1007/s00247-007-0574-2

[15] J. Park, J. Kim and J. Roh, "Hypoplastic Vertebral Artery: Frequency and Associations with Ischaemic Stroke Territory," Journal of Neurology, Neurosurgery \& Psychiatry, Vol. 78, No. 9, 2007, pp. 954-958. http://dx.doi.org/10.1136/jnnp.2006.105767

[16] Y. M. Chuang, C. C. Chen and C. P. Lin, "Vertebral Artery Hypoplasia May Contribute to Abnormal Vestibular Evoked Myogenic Potentials," Acta Neurologica Taiwanica, Vol. 18, No. 2, 2009, pp. 113-117.

[17] L. Morris, "Non-Union of the Vertebral Arteries: Case
Report,” British Journal of Radiology, Vol. 35, 1962, pp. 496-498.

http://dx.doi.org/10.1259/0007-1285-35-415-496

[18] K. Morimoto, M. Nagahata, S. Ono, H. Miura, F. Tsushima, H. Seino, et al., "Incidence of Unilateral Distal Vertebral Artery Aplasia: Evaluation by Combining Basiparallel Anatomic Scanning-Magnetic Resonance Imaging (BPAS-MRI) and Magnetic Resonance Angiography," Japanese Journal of Radiology, Vol. 27, No. 3, 2009, pp. 151-155. http://dx.doi.org/10.1007/s11604-008-0313-0

[19] M. Nagahata, Y. Abe, S. Ono, T. Hosoya and S. Uno, "Surface Appearance of the Vertebrobasilar Artery Revealed on Basiparallel Anatomic Scanning (BPAS)-MR Imaging. Its Role for Brain MR Examination," AJNR, Vol. 26, 2005, pp. 2508-2513.

[20] K. S. Caldemeyer, J. B. Carrico and V. P. Mathews, "The Radiology and Embryology of Anomalous Arteries of the Head and Neck," AJR, Vol. 170, No. 1, 1998, pp. 197203. http://dx.doi.org/10.2214/ajr.170.1.9423632

[21] J. J. Van Overbeeke, B. Hillen and C. A. Tulleken, “A Comparative Study of the Circle of Willis in Fetal and Adult Life. The Configuration of the Posterior Bifurcation of the Posterior Communicating Artery," Journal of Anatomy, Vol. 176, 1991, pp. 45-54.

[22] R. R. Edelman, H. P. Mattle, G. V. O'Reilly, K. U. Wentz, C. Liu and B Zhao, "Magnetic Resonance Imaging of Flow Dynamics in the Circle of Willis," Stroke, Vol. 21, No. 1, 1990, pp. 56-65.

http://dx.doi.org/10.1161/01.STR.21.1.56

[23] P. Scheel, C. Ruge, U. R. Petruch and M. Schöning, "Color Duplex Measurement of Cerebral Blood Flow Volume in Healthy Adults," Stroke, Vol. 31, No. 1, 2000, pp. 147150. http://dx.doi.org/10.1161/01.STR.31.1.147

[24] M. Schoning and B. Hartig,"The Development of Hemodynamics in the Extracranial Carotid and Vertebral Arteries," Ultrasound in Medicine \& Biology, Vol. 24, No. 5, 1998, pp. 655-662.

http://dx.doi.org/10.1016/S0301-5629(98)00029-5

[25] S. Chaturvedi, T. G. Lukovits, W. Chen and P. B. Gorelick, "Ischemia in the Territory of a Hypoplastic Vertebrobasilar System," Neurology, Vol. 52, No. 5, 1999, pp. 980-983.

[26] J. H. Park, J. M. Kim and J. K. Roh, "Hypoplastic Vertebral Artery: Frequency and Associations with Ischaemic Stroke Territory," Journal of Neurology, Neurosurgery \& Psychiatry, Vol. 78, No. 9, 2007, pp. 954-958. http://dx.doi.org/10.1136/jnnp.2006.105767

[27] F. Perren, D. Poglia, T. Landis and R. Sztajzel, "Vertebral Artery Hypoplasia: A Predisposing Factor for Posterior Circulation Stroke?" Neurology, Vol. 68, No. 1, 2007, pp. 65-67. http://dx.doi.org/10.1212/01.wnl.0000250258.76706.98

[28] S. Giannopoulos, S. Markoula, M. Kosmidou, S. H. Pelidou and A. P. Kyritsis, "Lateral Medullary Ischaemic Events in Young Adults with Hypoplastic Vertebral Artery," Journal of Neurology, Neurosurgery \& Psychiatry, Vol. 78, No. 9, 2007, pp. 987-989.

http://dx.doi.org/10.1136/jnnp.2006.106419 
[29] A. Lovrencić-Huzjan, V. Demarin, T. Rundek and V. Vuković, "Role of Vertebral Artery Hypoplasia in Migraine," Cephalalgia, Vol. 18, No. 10, 1998, pp. 684-686. http://dx.doi.org/10.1046/j.1468-2982.1998.1810684.x

[30] Y. M. Chuang, Y. C. Hwang, C. P. Lin and C. Y. Liu, "Toward a Further Elucidation: Role of Vertebral Artery Hypoplasia in Migraine with Aura," European Neurology, Vol. 59, No. 3-4, 2006, pp. 148-151. http://dx.doi.org/10.1159/000111878

[31] E. B. Ringelstein, H. Zeumer and D. Angelou, "The Pathogenesis of Strokes from Internal Carotid Artery Occlusion. Diagnostic and Therapeutical Implications,"
Stroke, Vol. 14, No. 6, 1983, pp. 867-875. http://dx.doi.org/10.1161/01.STR.14.6.867

[32] J. P. Kistler, A. H. Ropper and R. C. Heros, "Therapy of Ischemic Cerebral Vascular Disease Due to Atherothrombosis," The New England Journal of Medicine, Vol. 311, No. 2, 1984, pp. 100-105. http://dx.doi.org/10.1056/NEJM198407123110206

[33] F. B. Meyer, D. G. Piepgras, T. M. Sundt Jr. and T. Yanagihara, "Emergency Embolectomy for Acute Occlusion of the Middle Cerebral Artery," Journal of Neurosurgery, Vol. 62, No. 5, 1985, pp. 639-647. http://dx.doi.org/10.3171/jns.1985.62.5.0639 